\title{
Numerical Method for Cost-Weight Optimization of Stringer-Skin Panels
}

\author{
R. Curran* \\ Queen's University Belfast, Belfast, Northern Ireland BT9 5AG, United Kingdom \\ A. Rothwell ${ }^{\dagger}$ \\ Delft University of Technology, Kluyverweg 1, Delft, The Netherlands \\ and \\ S. Castagne ${ }^{*}$ \\ Queen's University Belfast, Belfast, Northern Ireland BT9 5AG, United Kingdom
}

\begin{abstract}
The need to integrate cost into the early product definition process as an engineering parameter is addressed. The application studied is a fuselage panel that is typical for commercial transport regional jets. Consequently, a semi-empirical numerical analysis using reference data was coupled to model the structural integrity of thin-walled structures with regard to material failure and buckling: skin, stringer, flexural, and interrivet. The optimization process focuses on direct operating cost (DOC) as a function of acquisition cost and fuel burn. It was found that the ratio of acquisition cost to fuel burn was typically $4: 3$ and that there was a $10 \%$ improvement in the DOC for the minimal DOC condition over the minimal weight condition because of the manufacturing cost saving from having a reduced number of larger-area stringers and a slightly thicker skin than that preferred by the minimal weight condition. Also note that the minimal manufacturing cost condition was slightly better than the minimal weight condition, which highlights the key finding: The traditional minimal weight condition is a dated and suboptimal approach to airframe structural design.
\end{abstract}

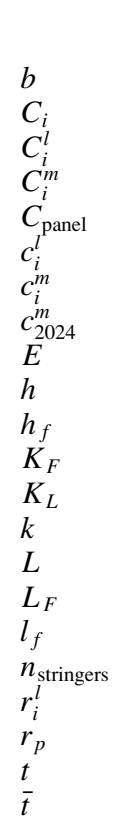

$=$
$=$
$=$
$=$
$=$
$=$
$=$
$=$
$=$
$=$
$=$
$=$
$=$
$=$
$=$
$=$
$=$
$=$
$=$
$=$
$=$

stringer pitch

total cost for part family $i$

labor cost for part family $i$

material cost for part family $i$

total cost of the panel

time factor, h/unit

material cost coefficient, \$/unit

material cost coefficient for $2024 \mathrm{~T} 3$ aluminum, $\$ / \mathrm{g}$

elastic modulus

stringer height

frame height

flexural buckling coefficient

local buckling coefficient

radius of gyration of stringer with attached skin

length

frame pitch

frame flange length

number of stringers

labor rate, $\$ / \mathrm{h}$

rivet pitch

thickness

equivalent (smeared) thickness

Presented as Paper 2004-2018 at the AIAA/ASMA/ASCE/AHS/ASC 45th Structures, Structural Dynamics, and Materials Conference, Palm Springs, CA, 19-22 April 2004; received 3 September 2004; accepted for publication 21 October 2004. Copyright (C) 2005 by R. Curran. Published by the American Institute of Aeronautics and Astronautics, Inc., with permission. Copies of this paper may be made for personal or internal use, on condition that the copier pay the $\$ 10.00$ per-copy fee to the Copyright Clearance Center, Inc., 222 Rosewood Drive, Danvers, MA 01923; include the code 0021-8669/06 \$10.00 in correspondence with the CCC.

* Senior Lecturer, School of Aeronautical Engineering, David Keir Building, Stranmillis Road. Member AIAA.

${ }^{\dagger}$ Professor, Structures and Computational Mechanics, Faculty of Aerospace Engineering.

${ }^{\dagger}$ Research Assistant, Centre of Excellence for Integrated Aircraft Technologies, School of Aeronautical Engineering, David Keir Building, Stranmillis Road. Member AIAA.

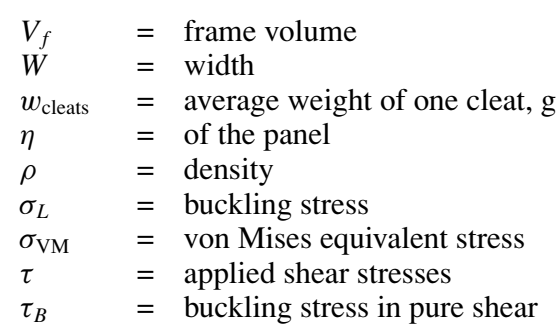

\section{Introduction}

$\mathbf{T}$ HIS paper presents the initial findings of a research study into the development of a numerical approach to the cost-weight optimization of aircraft stringer-skin panels. A key aim of the work is the development of a methodology that facilitates the optimal choice of design variables, with the ultimate objective function of minimizing the direct operating cost (DOC) of transporting that given weight of the aircraft structure during the aircraft's life span. Essentially, the optimization process considers the structural requirements, structural configuration, and manufacturing cost in generating a design that minimizes the cost to the airline operator. However, the study does not consider maintenance issues, nonrecurring costs, etc.

\section{Literature Review: Cost Integrated Design}

It is well documented in the literature that cost is an important attribute of any product and highly relevant to the engineering design process. ${ }^{1,2}$ Sheldon et al. have stated that customer affordability, product quality, and market timeliness are the three key elements of competitiveness. $^{3}$ They also point out that there are two fundamental engineering approaches to controlling cost, namely, 1) designing for cost and 2) costing for design. Within the aerospace community, Dean is well known for promoting such considerations within NASA (see Ref. 4). Although Sheldon et al. define the design for cost (DFC) methodology as being driven by management imposed cost targets, this is usually referred to specifically as design to cost (DTC), ${ }^{5}$ implying that a cost target is to be met and adhered to. DFC is taken generally to mean that the design process is mindful of cost. Many authors now believe that imposing strict target 
Production standards Material costs Labour rates

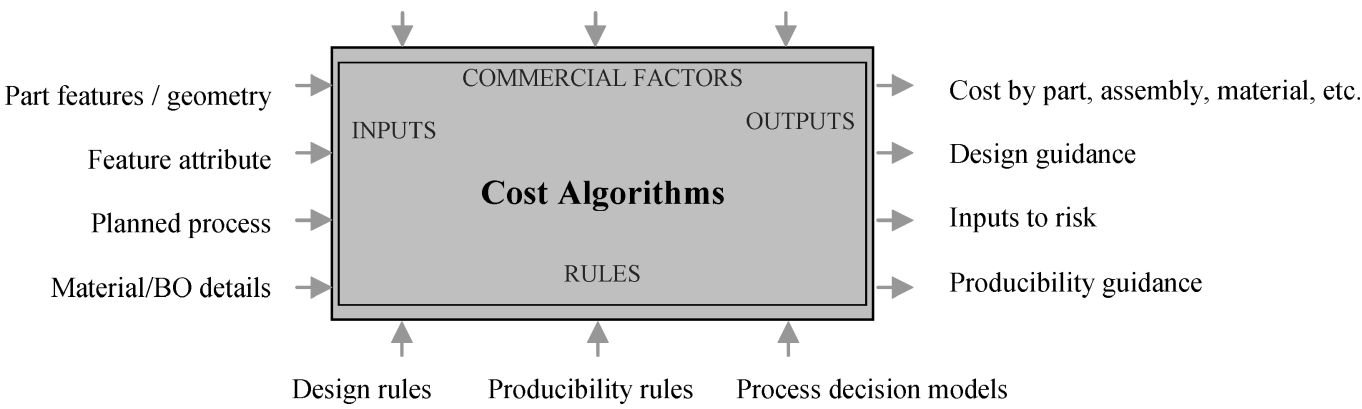

Fig. 1 Typical generic model of design-oriented cost model.

costing on engineering design, as for DTC, is not effective because it tends to result in inferior design that still overshoots the poor cost estimates used as guidance. ${ }^{6}$ Rather, it seems to be more important to give designers supportive costing tools that facilitate the product definition process by linking design decisions to cost impact.

Figure 1 shows a typical generic model of a cost-estimating tool that can be used within the design domain. ${ }^{7}$ However, most of these DFC/DTC tools are bespoke and highly customized within the aerospace industry. ${ }^{8}$ For example, Geiger and Dilts have presented an automated DTC tool that can be linked to a CAD package to provide the estimated cost of machined parts from a particular material. ${ }^{9}$ Within the aerospace community, this would be most relevant to the detailed design process for a range of parts from smaller complex machinings, but could be extended to larger fuselage frames of machined-finish aluminum forging, for example. The cost tool interprets the machined part using feature-based modeling ${ }^{10}$ and classes it accordingly using group technology. ${ }^{11}$ Various costing modules then plan and cost the machining process using a mixture of activity-based costing $(\mathrm{ABC})^{12,13}$ and analogous costing in a comparative manner. Taylor has also advocated a feature-based approach to aerospace cost estimating, and this has often been a mainstay of traditional aircraft cost estimators. $^{14}$

Analogous costing is also a traditional costing technique that uses the cost of a similar product to gain a first baseline estimate. Deviations in the design or manufacture of the new product are then used to account for alterations in the initial cost estimate. ${ }^{15}$ Apart from the analogous $\mathrm{ABC}$ and feature-based techniques, there are a range of other methods for generating the actual cost estimates from input data and constraints, ${ }^{16}$ including regression-oriented parametrics, ${ }^{17}$ bottom-up costing, fuzzy logic, ${ }^{18}$ and neural networks. ${ }^{19}$ It is the level of input data and the range of constraints that tend to differentiate these techniques and make them more or less suitable to a given application, especially according to the level of product and process definition available. The parametric estimating technique ${ }^{20,21}$ is very widespread and varies greatly from being purely statistical to more causal in nature, being linear, exponential (logarithmic linearity), or polynomial in form.

It is also well documented in the literature that the impact of cost needs to be introduced upfront at the concept design stage. Pugh has advised that top-down cost estimating should begin even before the aircraft development process begins. ${ }^{22}$ Thurston and Essington advocate a holistic approach to the design process that is appropriate at the concept stage, where a product is defined in terms of a measure of its utility value to the customer. ${ }^{23}$ This includes cost in a multi-attribute analysis ${ }^{24}$ of the design that can then be mathematically optimized. ${ }^{25}$ Another form of this design methodology has also been applied by Collopy and Eames to satisfy the holistic design requirements of an unmanned arial vehicle. ${ }^{26} \mathrm{~A}$ highlevel objective function that reflected the wider design requirements of both cost and performance is at the core of the method, providing a tradeoff mechanism that, through maximization, promotes the optimal choice of design parameters within stipulated ranges of constraint.

This type of approach can be traced back to much of the classic research within the aerospace industry into parametric optimization ${ }^{27}$ : the identification of key design parameters that drive performance and that can be optimized when combined in mathematical formula. Much of the current mainstream research in the industry is focused toward multidisciplinary optimization (MDO), whether at a high level or the lower level linking of discrete computational models. ${ }^{28}$ Marx et al. have linked MDO to life-cycle analysis (LCA) by defining high-level objective functions that encompass the lifecycle needs of aircraft, supported by necessary disciplinary models that facilitate the optimization process through the linkage defined by an objective function. ${ }^{29}$ In aerospace, LCA tends to be associated with military application, whereas the commercial sector focuses on DOC, being more associated with the cost of transporting a person a number of air miles at as low a cost as possible. There are various DOC models available, which tend to be of a parametric nature, ${ }^{30,31}$ that allow tradeoff of design parameters and that can be linked to manufacturing models to couple in the impact on production. ${ }^{6,16,32}$

It has been shown from the literature that aerospace manufacture is a key fundamental driver in cost integrated design, whether considering high-level cost control methodologies such as DFC/DTC or integrated design methodologies for the high-level concept stage or at the lower-level preliminary scheme and detailed stages. The impact of the work of Boothroyd and Dewhurst in highlighting the need for a methodology that links the impact of design decisions on manufacture is well documented. ${ }^{33}$ The major contribution, in addition to firmly establishing the design for manufacture and assembly (DFMA) principle, was in providing an analysis technique that quantitatively compared a given design with a theoretical baseline in terms of design complexity, classically with regard to part count and fastener count. Stoll has also addressed many of the organizational and implementation aspects of DFMA, ${ }^{34}$ whereas other authors were already reporting on the important linkage between DFMA and LCA. ${ }^{35}$

The basic principle of relevance to life-cycle cost (LCC) is still as prevalent an issue today as shown by Murman et al., who define better-faster-cheaper life-cycle needs in terms of value-oriented cost, performance, and time functions. ${ }^{36}$ The process technology aspects are addressed by considering lean practices for design, engineering, and manufacturing. Marx et al. have presented a parametric analytical solution for linking life-cycle needs back to design. ${ }^{29}$ They use the case study of a high-speed commercial transporter to investigate the best structural layout for the wing in terms of life-cycle requirements, including chordwise stiffened, spanwise stiffened, and biaxially stiffened structural layouts. A much more detailed analysis platform for the manufacturing cost drivers has been developed by Rais-Rohani, ${ }^{37}$ where he incorporates all of the relevant manufacturing issues in terms of parametrically defined complexity factors, including compatibility, complexity, quality, efficiency, and coupling. His work is integrated into the aircraft design process using a three-tier MDO methodology (see Ref. 38). 
For example, with respect to three alternate structural designs of a wing box (thin heavily stiffened skin, thick lightly stiffened skin, multispar), the authors advocate first setting out the structural design configuration, as well as defining materials, part manufacture, and assembly method. Second, a single- or multiple-optimization procedure is carried out according to some objective function with a multidisciplinary set of design and manufacturing constraints. Third, the design is validated and the cost estimates improved to allow for tradeoff, sensitivity studies, and optimization of the airframe structures.

With regard to the aircraft fuselage panels considered in this paper, the need to understand the linkage between material and process selection, structural design needs, and LCC has been driven by industrial needs in the face of ever tighter competition and demanding passenger requirements. Sandoz, a chief engineer on the Boeing 747, was already projecting a value-oriented approach to the integration of these needs for aircraft structures in 1973 (Ref. 39). Other authors have continued to address the impact on manufacturing by characterizing the various manufacturing processes for fuselage panel parts, ${ }^{40}$ along with the associated assembly processes, ${ }^{41}$ with respect to key design drivers and cost. Much of the work has again been industrial oriented with an interest in assessing the tradeoff between technologies or materials. ${ }^{42}$ However, there has been very little published work carried out in the linkage and simulation of accurate cost estimation and detailed structural requirements. Consequently, this paper sets out a methodology for the integration of cost into the airframe design process at the performance analysis stage so that proper tradeoff of design solutions can be carried out through explicit optimization procedures involving both structural performance and manufacturing cost.

\section{Genetic-Causal Cost Modeling}

Note from the literature review that there is not an established technique for the scientific modeling of manufacturing cost within engineering design. However, there are a number of aspects that can be seen consistently to relate to cost, that is, form or geometric definition, and production processes and materials. It is also evident that there are a number of ways in which to formulate relations quantitatively, but that statistical significance is a fitting manner in which to formulate relations that are sensitive to environmental noise yet characterized by certain generic aspects, typically relating to design information. The genetic-causal approach is proposed as a scientific approach to the modeling of manufacturing cost as arising from the work done in converting a raw material through a number of stages into a part that may then be assembled into a whole.

Within this paper, it is proposed that manufacturing cost be modeled using a methodology referred to as the genetic-causal method. This is achieved by 1) classifying the generic cost elements that are linked to particular genetic indicators and 2) developing causal parametric relations that link those genetic identifiers to the resultant manufacturing costs. In proceeding with a hierarchical designoriented classification, there are three key aspects that can be considered as genetic, cost being a result these aspects within the design definition. The relevant information from these three aspects can be thought of as bits of genetic information that are coded into the design and that give rise to cost. The actual cost, however, is only fixed if all things remain equal. Otherwise, environmental factors such as rates and interest will vary, and process cycle factors will vary depending on company efficiency. Therefore, any scientific cost prediction is truly termed an estimate because the prediction is the most likely potential cost given 1) the nature of the pure design and 2) the environmental factors that might additionally influence its manufacture.

The genetic-causal method utilizes the following indicators and hierarchy:

1) The first indicator is form, or the required shape: The classification according to form or geometric similarity is crucial for linking manufacturing cost into the design definition process. This may also include additional form definition in terms of identified features or higher-fidelity ratings of design information such as through complexity factors. It will be shown that a first-order classification is imposed in the presented study to identify skin, stringer, frame, cleat, and rivet as forms, whereas a second-order classification of lightening hole is used in conjunction with frame to improve the resolution of design information.

2) The second indicator is process, or the available conversions: The classification of physical form can then be matched to potential processes available to achieve those forms. There are two aspects to this: 1) the understanding of the various process stages and 2 ) the understanding of each of those processes. The significant stages in the production cycle are identified through the definition of a material conversion route, after which individual process models can be assigned to each stage. It is at this stage that cycle-time factors and established rates need to be introduced to characterize the processes relative to influential geometric information. For example, it will be seen that the form stringer and feature T-shape is first used to classify the stringer riveting, after which the cost is predicted using the design length of stringers in conjunction with a process performance rate and its cost rate.

3 ) The third indicator is material, or its required behavior: The choice of material is associated with the required behavior of the parts but is highly coupled to process selection, also through workability. Producers may preference a process and then work to satisfy material requirements, for example, developing stringer alloys that can be welded. However, it is clear that the material categorization contributes a raw material cost and treatment cost. This is a function of the material quantities required by the design form, but it is coupled to the process type in terms of material addition or material removal. A further complication with materials procurement is the degree of preprocessing, such as rolling, forming, or the extrusion of the stringer lengths. This need not affect the costing accuracy significantly, but does impinge on the clarity of the tradeoff studies within the context of the design process. However, the addition of bought-out and subcontracted items does require a procurement factor.

Note from the preceding three aspects that design information is absolutely fundamental to the understanding of manufacturing cost, according to the genetic cost coding imposed by the designer through the impact of their decisions on form, process, and material. We have also recognized the impact of environmental noise on factoring the causal impact from form, process, and material. However, these causal relations can now be modeled using statistical significance with appropriate normalization for the environmental factors. This results in scientifically based relations that numerically link cost to causal sources embedded in the design definition. Apart from being a highly generic cost modeling technique, the genetic-causal technique is also extremely well suited to use within an integrated design platform because changes in the design for performance benefit can be mapped through to cost to trade off manufacturing cost relative to some global objective function directly, as exemplified later in this paper.

\section{Manufacturing Cost Analysis}

The manufacturing cost analysis is based on empirical data gathered from Bombardier Aerospace Shorts and is typical for regional passenger jets. These data are provided in the form of engineering drawings and a work breakdown structure (WBS) that contains the cost information within several Excel spreadsheets.

The cost modeling methodology for the linkage between manufacturing and design imposes a breakdown of the cost into a number of elements, including material cost, fabrication cost, and assembly cost, so that it can be formulated into semi-empirical equations to be linked to the same design variables as considered in the structural analysis.

\section{Actual Cost of the Panel}

The generic product families used on a typical stringer-skin panel are the panel itself, which forms the skin of the aircraft; the stringers and the frames that support it in the longitudinal and lateral directions, respectively; the cleats that are present at every 


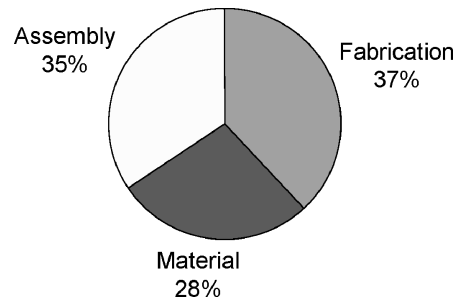

Fig. 2 Total cost breakdown.

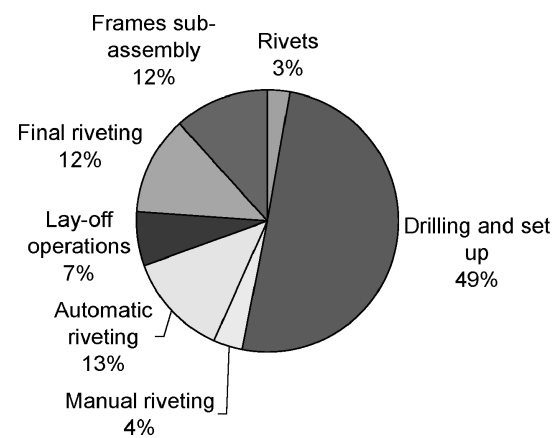

Fig. 3 Actual assembly cost.

stringer-frame junction in the studied panel; and the rivets that hold it all together. The overall breakdown in the manufacturing cost analysis is summarized in Eq. (1), expressed in term of these product families (skin, stringers, frames, cleats, and rivets):

$$
C_{\text {panel }}=\sum_{i=1}^{5} C_{i}=C_{\text {skin }}+C_{\text {stringers }}+C_{\text {frames }}+C_{\text {cleats }}+C_{\text {rivets }}
$$

where $C_{\text {panel }}$ is the total cost of the panel and $C_{i}$ the total cost for the part family $i$.

Three major types of costs are to be taken into account: material costs, fabrication costs, and assembly costs. In accordance with the empirical data provided for the stringer-skin panel, the repartition of these costs is shown in Fig. 2. Note that the fabrication costs only include the in-house labor costs. This means that for several parts the material costs also include fabrication costs. For example, relative to the particular industrial data being used, the material cost for the skin panel already includes fabrication costs because the skin is supplied to the assembly stage in a ready condition, that is, at the correct thickness and to net trim at the edges. Likewise, the stringer material cost already includes the extrusion process. A true raw material cost is available for the cleats and the frames. The rivets are standard commercial parts, that are received in their manufactured state. From a costing point of view, the rivets are part of the material costs.

With the assumptions just mentioned, the total cost breakdown in Fig. 2 shows that the repartition between the three cost elements are almost equivalent, the material being a little less important.

The assembly or riveting cost can then be divided into different components, as shown in Fig. 3. The rivets have been included in Fig. 3 because, even if they are supposed to be part of the material costs in Fig. 2, they take part in the assembly process.

It is obvious that the drilling cost is the most important part. The drilling cost also includes the cost linked to the setup, that is, the cost of positioning all parts. The cost of the rivets themselves is very low (only $3 \%$ ). The remaining cost is divided into the costs related to the subassembly of the frames, the manual and automatic riveting (assuming that $85 \%$ of the rivets are automatic), the final riveting, and the layoff operations such as cleaning and inspection.

Additional parts such as antennas, lighting, or electrical provisions have not been introduced into the cost equation because they are not part of the essential structural components of the panel and do not influence the optimization process. The cost of these additional parts, which only represents $8 \%$ of the total cost of the panel (Fig. 4), can be added at the end of the estimation process if we want to be more accurate.

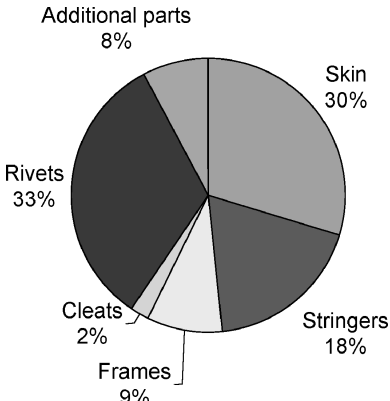

Fig. 4 Panel cost breakdown.

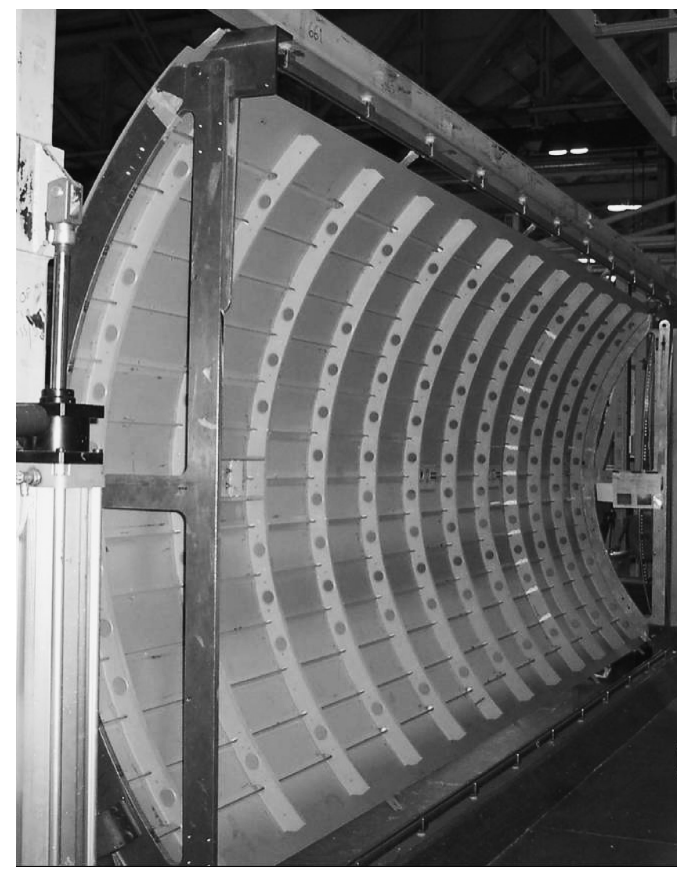

Fig. 5 Section of panel.

\section{Derivation of Estimating Equations}

For each family of parts defined in Eq. (1), semi-empirical equations are determined. For clarity's sake, we divide the cost in two components only: the material $\operatorname{cost} C_{i}^{m}$ and the labor $\operatorname{cost} C_{i}^{l}$, the labor cost corresponding either to fabrication costs or assembly costs. Each factor of Eq. (2) is then computed as follows:

$$
C_{i}=C_{i}^{m}+C_{i}^{l}
$$

Throughout this section, the superscript $m$ and $l$ are used to refer to material or labor, respectively.

The costing coefficients appearing in the equations are determined empirically on the basis of the drawings and WBS provided by the industrial partner. Each coefficient is computed, for each family part and cost element, as an average of the actual cost data found in the WBS spreadsheets. Three types of coefficients are used in the equations, on one hand the material coefficient $c_{i}^{m}$ and on the other hand the two labor coefficients: the time factor $c_{i}^{l}$ (hr/[unit]), which already includes such things as learning curve or breaks, and the wage rate per hour $r_{i}^{l}$.

Figure 5 represents a section of the panel. In Fig. 5, the stringers and the frames can be distinguished, as can the rivets. All of the geometrical data are issued from the representations: panel length, panel width, panel thickness, frame pitch, frame rivet pitch, frame cross-section dimensions, stringer pitch, stringer rivet pitch, and stringer cross-section dimensions.

Other parts, such as antenna plates, which also appear in Fig. 5, are not taken into account for the cost modeling. Indeed, the antennas are not part of the essential structural components of the panel, and the main purpose of this estimate is to optimize the panel according to cost and not to define a complete cost model for the panel. 


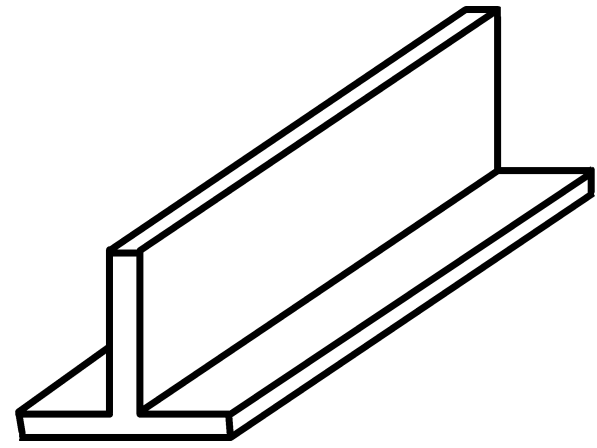

Fig. 6 T-shape stringer.

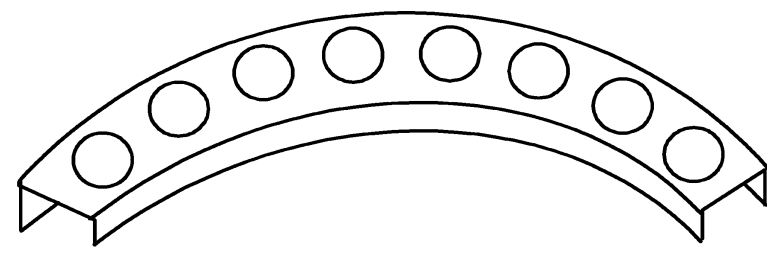

Fig. 7 Frame.

Skin Panel

For the skin, the material cost is modeled as follows for panel length $L$, width $W$, thickness $t$, material density $\rho$, and the empirically derived skin material cost coefficient $c_{\text {skin }}^{m}$ :

$$
C_{\text {skin }}^{m}=L W t \rho c_{\text {skin }}^{m}
$$

Whereas the labor cost is characterized by

$$
C_{\text {skin }}^{l}=L W r_{\text {skin }}^{l} c_{\text {skin }}^{l}
$$

where $r_{\text {skin }}^{l}$ is the skin labor cost per hour and $c_{\text {skin }}^{l}$ is the empirically derived skin labor coefficient.

As mentioned before, the material cost for the skin panel does not only include raw material, but also additional procedures such as rolling and chemimilling.

\section{Stringers}

Three different stringers types are used in the actual panel: T-shape, L-shape, and mix-shape (T-shape ending with an L-shape). For the estimate, we suppose that all of the stringers have a T-shape so that they are maintained by two rows of rivets. An example of such an stringer is shown in Fig. 6 .

The material cost for stringers includes the extrusion process. This suggests that the cost is function of the length. Under the assumption that the length of the stringer corresponds to the length of the panel $L$, given the empirically derived stringer material cost coefficient $c_{\text {stingers }}^{m}$,

$$
C_{\text {stingers }}^{m}=n_{\text {stringers }} L c_{\text {stingers }}^{m}
$$

where $n_{\text {stringers }}$ is the number of stringers obtained by dividing the width of the panel $W$ by the stringer pitch found by measurement from the drawings.

The labor cost is also a function of the stringer length,

$$
C_{\text {stingers }}^{l}=n_{\text {stringers }} L r_{\text {stingers }}^{l} c_{\text {stingers }}^{l}
$$

where $r_{\text {stingers }}^{l}$ is the stringers labor cost per hour and $c_{\text {stingers }}^{l}$ is the stringers labor coefficient (hours per millimeter).

\section{Frames}

Figure 7 shows an example of the frames used to strengthen the panel. These frames are manufactured from 2024 T3 aluminum alloy.

The material cost for the frames is computed as a function of the volume. The frames are supposed to be straight and of a $\mathrm{C}$ cross section. We suppose that they extend over the width of the panel so that their length corresponds to the panel width $W$. All frame dimensions are deduced from Fig. 7. If $t_{f}$ is the frame thickness, $h_{f}$

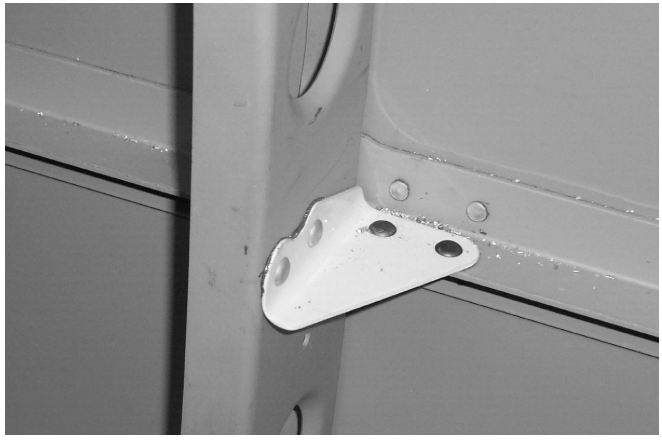

Fig. 8 Cleat.

the frame height, and $l_{f}$ the frame flange length, the volume $V_{f}$ of one $\mathrm{C}$ shape frame is

$$
V_{f}=\left[\left(2 l_{f}+h_{f}\right) t_{f}-2\left(t_{f}\right)^{2}\right] W
$$

Given the number of frames $n_{\text {frames }}$, the material density $\rho$, and the material cost coefficient for the $2024 \mathrm{~T} 3$ aluminum $c_{2024}^{m}$, the material cost for the frames is computed by

$$
C_{\text {frames }}^{m}=n_{\text {frames }} V_{f} \rho c_{2024}^{m}
$$

The frame labor coefficient $c_{\text {frames }}^{l}$ (hours per hole) is supposed to be directly proportional to the number of lightening holes in the frames $n_{\text {holes. }}$. If $r_{\text {frames }}^{l}$ is the frames labor cost per hour, the total frames labor cost can be calculated as follows:

$$
C_{\text {frames }}^{l}=n_{\text {frames }} n_{\text {holes }} r_{\text {frames }}^{l} c_{\text {frames }}^{l}
$$

\section{Cleats}

The cleats are used to attach the frames to the stringers as well as being load distributors, as shown in Fig. 8.

Using the information of the bill of material and the detailed drawings, we can conclude that, for this panel, one cleat is used at each stringer-frame junction. As for the frames, they are manufactured from 2024 T3 aluminum. Three types of cleats are used in the panel, and so the weight of one average cleat $w_{\text {cleats }}$ has been determined empirically.

The total raw cost of the cleats is given as

$$
C_{\text {cleats }}^{m}=n_{\text {cleats }} w_{\text {cleats }} c_{2024}^{m}
$$

where $n_{\text {cleats }}$ is the number of cleats and $C_{2024}^{m}$ the material cost coefficient defined before.

The fabrication cost related to the cleats is

$$
C_{\text {cleats }}^{l}=n_{\text {cleats }} r_{\text {cleats }}^{l} c_{\text {cleats }}^{l}
$$

where $r_{\text {cleats }}^{l}$ is the cleat labor cost per hour and $c_{\text {cleats }}^{l}$ (hours per cleat) is the cleat labor coefficient.

Rivets

We include in this section all of the processes linked with the rivets, that is, all of the assembly processes. Like the fabrication costs, the assembly costs defined in this section are labor costs, except for the material cost of the rivets.

Two different types of rivets are used for the general panel (A type and B type). The cost of each of these types of rivets is calculated as the average cost of their respective variants from the information found on the WBS spreadsheet.

A-type rivets are used to connect the cleats to the stringers and frames. Each cleat uses four rivets, two to connect to the stringers and two to the frames. Therefore, the total number of A-type rivets $n_{\mathrm{A} \text { rivets }}$ is equal to four times the number of cleats.

B-type rivets are used on the stringers and frames. The number of rivets on one stringer is two times the stringer length divided by the stringer rivet pitch because we have two rows of rivets for the T-shape stringers. Likewise, the number of B-type rivets on one frame is the frame length divided by the frame rivet pitch. Only one row of rivets is needed for the frames. The total number of 
B-type rivets $n_{\mathrm{B}}$ rivets is the number of rivets on the stringers plus the number of rivets on the frames, minus the common rivets that would be overlaid by both components, that is, two times the number of stringer-frame junctions.

If $c_{\mathrm{A} \text { rivets }}^{m}$ is the cost of one A-type rivet and $c_{\mathrm{B} \text { rivets }}^{m}$ the cost of one $\mathrm{B}$-type rivet, the total material cost for the rivets is

$$
C_{\text {rivets }}^{m}=n_{\mathrm{A} \text { rivets }} c_{\mathrm{A} \text { rivets }}^{m}+n_{\mathrm{B} \text { rivets }} c_{\mathrm{B} \text { rivets }}^{m}
$$

The first stage in the assembly process is the subassembly of frames, which consists of riveting reinforcements on the frames. It is assumed that the cost of this process is proportional to the length of the frame. If $r_{\text {sa-fr }}^{l}$ is the frame subassembly labor cost per hour (dollars per hour) and $c_{\mathrm{sa}-\mathrm{fr}}^{l}$ (hours per millimeter) the frame subassembly labor coefficient, the total subassembly cost for the frames is

$$
C_{\text {sa-fr }}^{l}=n_{\text {frames }} r_{\text {sa-fr }}^{l} c_{\text {sa-fr }}^{l}
$$

For the whole panel, the assembly process can be divided into the following steps: First, the holes for the rivets are drilled and reamed to the required dimensions; then, rivets are inserted, beginning with the manual rivets and completed by the autoriveting process; finally, layoff operations for the panel and the final riveting and assembly are realized.

The drilling and reaming of the holes is assumed constant for both types of rivets and is a function of rivet number. Therefore, the total cost for drilling and reaming is

$$
C_{\mathrm{drill}}^{l}=\left(n_{\mathrm{A} \text { rivet }}+n_{\mathrm{B} \text { rivet }}\right) r_{\text {drill }}^{l} c_{\text {drill }}^{l}
$$

where $r_{\text {drill }}^{l}$ is the drilling and reaming labor cost per hour (dollars per hour) and $c_{\text {drill }}^{l}$ (hours per rivet) the rivet labor coefficient.

The riveting process can be split into two sections, manual riveting and autoriveting. It is assumed that the A-type rivets that connect the cleats to the frames and stringers are manually riveted. Also, a certain number of B-type rivets are required to hold the panel together while it is autoriveted. It is assumed that these rivets are the end rivets of the stringers and frames and the rivets at the stringer-frame junctions. Assuming that all of the other rivets are automatically riveted, we found that, for this particular panel, $85 \%$ of the rivets were autorivets.

If $n_{\text {man-riv }}$ is the number of manual rivets, $r_{\text {man-riv }}^{l}$ the manual riveting labor cost per hour (dollars per hour), and $c_{\text {man-riv }}^{l}$ (hours per rivet) the manual riveting labor coefficient, we have, for the total manual riveting labor cost,

$$
C_{\text {man-riv }}^{l}=n_{\text {man-riv }} r_{\text {man-riv }}^{l} c_{\text {man-riv }}^{l}
$$

Likewise, if $n_{\text {auto-riv }}$ is the number of automatic rivets, $r_{\text {auto-riv }}^{l}$ the automatic riveting labor cost per hour (dollars per hour), and $c_{\text {auto-riv }}^{l}$ (hours per rivet) the automatic riveting labour coefficient, the total automatic riveting labor cost is

$$
C_{\text {auto-riv }}^{l}=n_{\text {auto-riv }} r_{\text {auto-riv }}^{l} c_{\text {auto-riv }}^{l}
$$

The layoff operations, such as cleaning and inspection, are assumed to be a function of the area of the panel. If $r_{\text {layoff }}^{l}$ is the panel layoff operations cost per hour (dollars per hour) and $c_{\text {layoff }}^{l}$ (hours per square millimeter) the panel layoff operations labor coefficient, the total the panel layoff operations cost for the panel is

$$
C_{\text {layoff }}^{l}=L W r_{\text {layoff }}^{l} c_{\text {layoff }}^{l}
$$

The final riveting and assembly procedures are calculated per rivet. The total final procedures cost is

$$
C_{\text {final-riv }}^{l}=\left(n_{\mathrm{A} \text { rivet }}+n_{\mathrm{B} \text { rivet }}\right) r_{\text {final-riv }}^{l} c_{\text {final-riv }}^{l}
$$

where $r_{\text {final-riv }}^{l}$ is the final procedures labor cost per hour (dollars per hour) and $c_{\text {final-riv }}^{l}$ (hours per rivet) the final procedures labor coefficient.
The total labor cost associated with the assembly process can be computed by adding Eqs. (13-18). The labor component of the total rivet and assembly costs $C_{\text {rivets }}^{l}$ is

$$
C_{\text {rivets }}^{l}=C_{\text {sa-fr }}^{l}+C_{\text {drill }}^{l}+C_{\text {man-riv }}^{l}+C_{\text {auto-riv }}^{l}+C_{\text {layoff }}^{l}+C_{\text {final-riv }}^{l}
$$

\section{Results of the Estimation}

As a first validation, the total cost of the panel has been calculated using, on the one hand, the raw data of the WBS spreadsheets and, on the other hand, the average equations of the preceding sections for a standard panel having the same dimensions. The comparison of the actual cost of the panel and the estimated cost is shown in Figs. 9-11. The cost data and estimates have been normalized for proprietary reasons relative to the total actual cost.

Figure 9 shows the breakdown of material costs. Note that the panel is by far the most significant expenditure. The errors on the estimated values are small except for the frames $(32 \%)$. This is

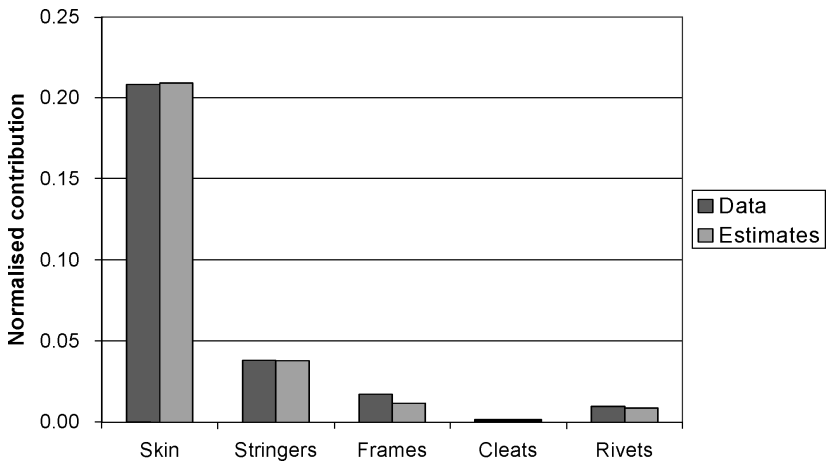

Fig. 9 Comparison of material costs.

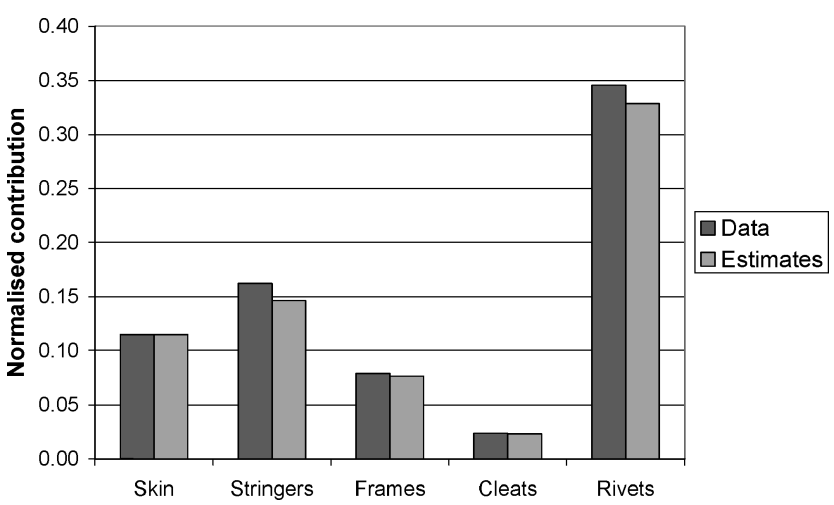

Fig. 10 Comparison of labor costs.

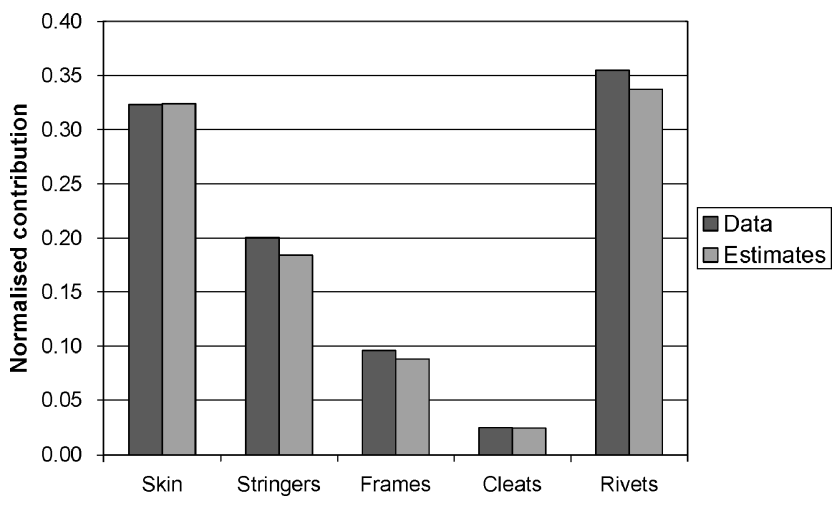

Fig. 11 Comparison of total costs. 
due to a lack of data concerning the frame dimensions. This part of the estimate will be corrected as soon as new data are available. A small error (10\%) is also perceptible concerning the rivets. This underestimation comes from the number of rivets that appear in the bill of material being greater than the number of rivets we deduce from the rivet pitch and the component length. Some rivets are probably used for additional operations not detailed in the estimates.

Alternatively, Fig. 10 shows the breakdown of labor costs for the various product families that constitute the stringer-skin panel. Note that the labor cost associated with the rivets is now most significant, and the stringers are also of great influence. However, note that, as stated earlier, the panel in this analysis was taken to arrive in finished net trim form and the stringers in the extruded form. That explains why the material cost was high for the panel. Likewise, the material cost for the stringers was also high due to the initial fabrication processes to make them ready for the assembly shop.

With regard to the labor cost, small errors appear in Fig. 10 for the stringers and the rivets for the same reason as that for the material cost, that is, greater quantities in the bill of material than can be deduced from the panel dimensions. This was already mentioned for the rivets, but the same problems appeared for the stringers whose total length in the costing data is greater than the number of stringers multiplied by the length of the panel. Actually, the stringers cost should be overestimated because we consider for the estimates that stringers cover the whole length of the panel, but in the actual panel they are a little bit smaller. The cost data for the stringers will be corrected as soon as more information is available.

Finally, the overall breakdown in total manufacturing costs is shown in Fig. 11, which corresponds to the addition of Figs. 9 and 10. The same remarks can be made regarding the errors for the rivets and the stringers. For the frame, the error is not so important when we take the total cost.

Figure 11 shows that the greater expenditure comes actually from the rivets, that is, from the assembly process and from the skin itself, each totaling between 30 and $35 \%$ of the total cost. Then come the stringers with $20 \%$ of the cost, followed by the frames and the cleats.

The simple cost model developed will be used in the optimization section to compute the manufacturing and material costs appearing in the optimization procedure. The cost model includes all of the equations proposed in this section, as well as the empirical coefficients defined on the basis of the industrial data.

\section{Structural Analysis}

For structural analysis the panel is modeled as shown in Fig. 12, where $b$ is the stringer pitch, $h$ the stringer height, $t$ the skin thickness, and $t_{s}$ the stringer thickness. The panel can be loaded under uniform compression, with loading intensity $p$, or under compression combined with a uniform shear flow. Failure modes considered are flexural buckling (long wave), local buckling (short wave) interrivet buckling (buckling of the skin between rivets), and material failure based on the allowable stress of the aluminum alloy material. Note that local buckling is not permitted, that is, no postbuckled design is considered in the present study. Explicit formulas are derived for each of these modes to facilitate their use in combination with cost formulas in a cost-weight optimization. Such formulas are inevitably an approximation of the real behavior of the panel (as

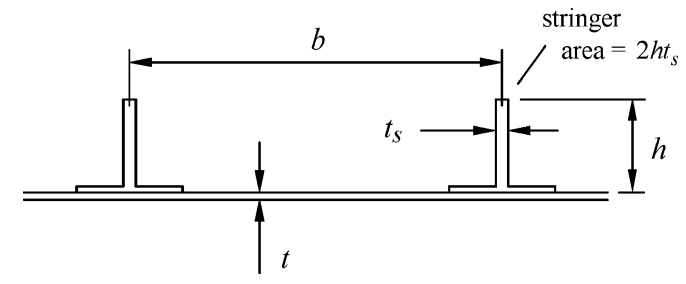

Fig. 12 Modeling of panel for structural analysis. might be obtained, for example, by a full numerical analysis) but are regarded as adequate at the current stage of the work. Furthermore, the intention is to develop a design tool that is both straightforward to use and readily programmed. Geometric constraints are applied in the subsequent optimization to avoid unrealistic designs.

For flexural buckling, the panel is assumed to be simply supported at the frames and wide enough that there is no interference between adjacent stringers. Euler's formula then gives for the flexural buckling stress $\sigma_{F}$,

$$
\sigma_{F}=\pi^{2} E /\left(L_{F} / k\right)^{2}
$$

This formula is conveniently rewritten

$$
\sigma_{F}=K_{F} E\left(b / L_{F}\right)^{2}
$$

in which the flexural buckling coefficient $K_{F}$ can be expressed as an explicit function of the ratios $h / b$ and $t_{s} / t$.

For local buckling, the buckling stress $\sigma_{L}$ is given by

$$
\sigma_{L}=K_{L} E(t / b)^{2}
$$

For convenience, the data used for the local buckling coefficient $K_{L}$ are for a simple blade-stiffened panel, that is, the flanges forming the attachment to the skin are neglected. This is to take advantage of existing published data. An initial check showed that this makes little difference to the result. An improved set of local buckling coefficients will be incorporated at a later stage. Values of $K_{L}$ are taken from data in the Engineering and Science Data Unit (ESDU) Structures Series ${ }^{43}$ (Fig. 13). (Note that Fig. 13 is purely for illustration. Sufficient data are available in Ref. 43 for a good curve fit. If necessary, ESDU also offers a computer program to calculate $K_{L}$ for a panel of unrestricted dimensional ratios.) The local buckling data referred to take account of interaction between the stringer and the skin, which would otherwise lead to some significant error. A polynomial approximation is used to represent the local buckling coefficient in the present analysis. A fourth-degree expression is found sufficient to give accuracy to within $3 \%$ in the region of interest. However, to capture the discontinuity seen in Fig. 13 at higher values of $t_{s} / t$ (due to sudden change in wavelength), separate expressions are necessary for the different parts of the curves.

For local buckling under combined compression and shear, the well-known parabolic interaction formula is used. Buckling occurs when

$$
\sigma / \sigma_{L}+\left(\tau / \tau_{B}\right)^{2}=1
$$

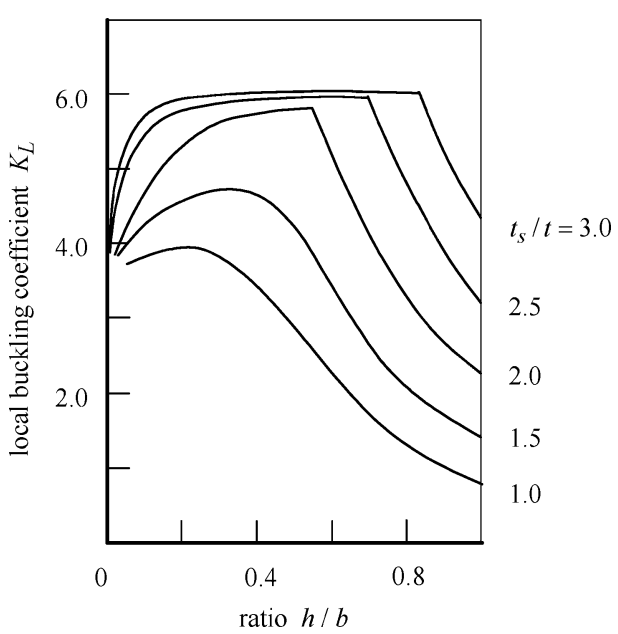

Fig. 13 Local buckling coefficient $K_{L}$. 
where $\sigma$ and $\tau$ are the applied compressive and shear stresses, respectively, and

$$
\tau_{B}=K_{S} E(t / b)^{2}
$$

where a representative value of the buckling coefficient is taken to be $K_{S}=4.83$.

For the interrivet buckling stress $\sigma_{R}$, the usual empirical formula ${ }^{44}$ is used,

$$
\sigma_{R}=K_{R} E\left(t / r_{p}\right)^{2}
$$

in which $K_{R}=2.46$ for conventional, round-head rivets and $r_{p}$ is the rivet pitch.

For the material stress limitation, an appropriate value of allowable stress is used when the panel is loaded under pure compression. Note that this is simply a cutoff value, that is, at this stage no consideration is given to reduction in (tangent) modulus with the approach of yielding. The stress levels in this study are low enough to make use of a reduced modulus unnecessary. However, this is readily incorporated without departing from the intention of employing explicit formulas for all failure modes. Under combined compression and shear, the von Mises equivalent stress $\sigma_{\mathrm{VM}}$ is used:

$$
\sigma_{\mathrm{VM}}=\sqrt{\sigma^{2}+3 \tau^{2}}
$$

This is again related to the allowable compressive stress of the material.

To assess the compromise reached in a cost-weight optimization, it is useful also to calculate the so-called efficiency $\eta$ of the panel. In compression, the theoretical efficiency is based on simultaneous flexural and local buckling, that is, at stresses below the material limitation. With applied stress $\sigma$,

$$
\sigma=p / \bar{t}
$$

dimensions $b$ and $t$ can be eliminated between Eqs. (21), (22), and (27) to give an efficiency formula,

$$
\sigma=\eta \sqrt{p E / L_{F}}
$$

in which $\eta=\left(K_{F} K_{L} / C^{2}\right)^{1 / 4}$ and $C=\bar{t} / t$.

Note that the local buckling coefficient $K_{L}$ appears to the power one-fourth in the formula for $\eta$, indicating that a small error in the polynomial expression to calculate $K_{L}$ will be of little consequence. A maximum efficiency $\eta$ can be deduced for the panel, with corresponding values of the ratios $h / b$ and $t_{s} / t$. The efficiency achieved in a real design will inevitably be less, in particular due to the small stringer pitch associated with the theoretical optimum, which would generally be impractical as well as expensive in manufacture.

\section{Optimization}

\section{Method of Optimization}

It has been shown in the literature review that there are various ways of driving the design process to be mindful of cost, but that this is generally achieved through the formulation of a more holistic objective function that is multidisciplinary in nature. This work is concerned with linking and trading off structural efficiency with manufacturing cost. Structural efficiency is already a tradeoff between maximizing material strength utilization and reducing weight ${ }^{45}$ whereas manufacturing cost is a tradeoff between specified design requirements (within tolerance) and process capability. ${ }^{46}$ Equation (29) highlights that the tradeoff can be achieved through the minimization of DOC:

$$
\begin{gathered}
\mathrm{DOC}=f n \text { (acquisition, fuel burn, maintenance, crew } \\
\text { and navigation, ground services) }
\end{gathered}
$$

However, for the purposes of the structural design tradeoff, all DOC drivers can be said to be fixed, apart from the acquisition cost and fuel burn. The neglected elements can be said to be of much less importance to the structural airframe designer, where, for example, even airframe maintenance has been estimated by Sandoz ${ }^{39}$ to be of the order of only $6 \%$ relative to the systems and the powerplant. Acquisition cost is driven by the cost of borrowing/investing money to pay for the cost of the aircraft amortized unit manufacture, plus a $15 \%$ profit margin, for example, and can again be simplified and stripped of overheads, contingency, etc., to be a function of the cost of manufacture for design tradeoff purposes. Fuel burn is a function of the specific fuel consumption and the cost of fuel and can, therefore, be said to be a function of weight in the current context.

For the purposes of structural optimization relative to DOC, it is simple to use some estimate of the cost of transporting each unit weight of structure over the life span of the aircraft, effectively being a cost per unit mass distance with units of either British pounds per kilogram kilometer or dollars per pound meter, for example. With respect to the isolation of manufacturing cost and structural weight being the key DOC drivers, it can be seen that manufacturing cost has a direct relation to the magnitude of DOC/unit mass distance, and weight is its multiplier. Therefore, one cannot assume use of a fixed figure for the DOC estimate within the optimization process, but rather a more inclusive weighted formula that includes the direct relation of manufacturing cost as well as the more obvious one of weight. Essentially, to optimize according to an objective function that only included a fixed DOC/unit weight distance would lead to the improper assessment of the minimum manufacturing cost condition as occurring at that point at which the corresponding weight leads to minimum DOC, rather than the minimum manufacturing cost being the decider. The minimum manufacturing cost will not necessarily reflect the minimum weight, as shown by Rais-Rohani and Greenwood. ${ }^{38}$

Note from the preceding discussion that a change in manufacturing cost must be linked through the impact on both acquisition cost (AC) and fuel burn (FB) (at that associated weight), whereas a change in weight is linked through FB alone. Figure 14 shows that a $50 \%$ weighting for $\mathrm{AC}$ and $15 \%$ weighting for $\mathrm{FB}$ is reasonable for the DOC split for an aircraft in the regional aircraft sector, in keeping with the panels sizing addressed in the paper. Consequently, the manufacturing cost (MFC) in the DOC equation used as the objective function in the optimization procedure is as follows, to be multiplied by a weight factor $n$ for an assessment of the cost penalty relative to the varying DOC scenario presented by the manufacturing solution,

$$
\mathrm{DOC}=\mathrm{FB}+\mathrm{AC}=\mathrm{FB}+n \cdot \mathrm{MFC}
$$

According to Fig. 14 and to the results of the optimization for efficiency, which is used as the reference case throughout this paper, typical values of $n$ would be 2 and 3.5, for example.

\section{Results and Discussion}

For cost-weight optimization of the panel, a marginal saving in the DOC of the aircraft, that is, savings directly attributable to the design of the panel, is assumed to be made up of a saving in manufacturing cost set off against a fixed-cost penalty for any increase in structure weight. The fixed-cost penalty is based on the FB of a typical civil transport aircraft, with normal utilization over its useful life, expressed in terms of its all-up weight. If

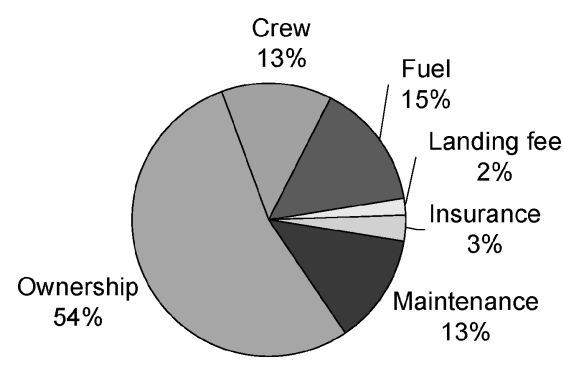

Fig. 14 LCC breakdown for CRJ series. ${ }^{47}$ 
a reduction in the manufacturing cost of the panel by redesign results in a weight increase, this implies some increase in the cost of fuel consumed by the aircraft over its entire service life. Minimization of this total cost, that is, MFC plus fixed-cost penalty, is the basis of the optimization performed here. Possible consequences of change in design for durability or maintenance costs are not considered at the present stage. It is also assumed that any weight increase is marginal and does not imply reduction in performance of the aircraft. Note that additional fuel costs are paid for over the life of the aircraft, whereas MFC are met at the outset. A fixed-cost penalty (often referred to as the economic value of weight saving) of 300 U.S. dollars per kilogram has been adopted, this amount having been adjusted to reflect interest on the initial investment.

For the panel considered in this study, the various formulas for MFC and structural analysis the preceding sections have been incorporated into a Microsoft Excel spreadsheet. MFC is subdivided into material cost and labor cost, identifying individual components of the panel and its assembly for a cost estimate directly related to the design of the panel. The structural analysis simply ensures that the panel continues to withstand the load applied to it. Because of the explicit nature of both sets of formulas, effective use could be made of the Solver optimization routine in Excel, which employs a generalized reduced gradient method. Formulas for the different modes of failure developed in the structural analysis serve as constraints in the optimization (together with certain other constraints arising from the limits of validity of the local buckling data). In turn, the weight of the panel, its bare material cost, the total MFC, that is, including material cost, and the marginal saving in direct operating cost as described earlier were taken as the objective function. The active design variables were chosen to be stringer pitch $b$, stringer height $h$, skin thickness $t$, stringer thickness $t_{s}$, and rivet pitch $r_{p}$. The last was chosen because it makes a major contribution to the cost of manufacture, whereas the other four are, of course, primary variables in the design of a stringer-skin panel, as well as having significant influence on MFC. Other details, such as the cleats forming the attachment of the panel to fuselage frames, vary in number, but no specific optimization of these was undertaken. Nevertheless, these, and an appropriate part of the frame weight, are included in the total weight of the panel. The frame pitch $\left(L_{F}=634 \mathrm{~mm}\right)$ was not varied during optimization.

For the present study, the panel was loaded in pure compression, at a structural index value $p / L_{F}=0.5 \mathrm{~N} / \mathrm{mm}^{2}$. This is a relatively small value, resulting in a low stress level in the panel, but it is appropriate to the design of panel from which the actual cost data were extracted. The panel was first optimized for maximum theoretical efficiency $\eta$. In fact, this is equivalent to minimizing the cross-sectional area of the skin and stringers, but excludes cleats, rivets, and other secondary items. A maximum efficiency $\eta=0.693$ was found for the panel with its particular stringer type. The total weight of this optimized panel, that is, now including the so-called secondary items, was calculated to be $10.8 \mathrm{~kg} / \mathrm{m}^{2}$, and this was used as the reference for a decrease or increase in weight in the subsequent optimizations. Similarly, the estimated cost of the panel optimized for maximum efficiency $\eta$ was used as the reference for subsequent decrease or increase in the cost of the panel. All cost savings are related to the estimated cost of the initially optimized panel rather than to the actual cost of the panel from which cost data have been extracted (as might have been considered more appropriate) because the actual loading on the latter panel was more complex than the single loading case considered here and there were other design requirements to satisfy as well. The optimization was then repeated for minimum total weight, minimum material cost, minimum total MFC, and minimum DOC. No problems with convergence were experienced during optimization, and, as a result of the explicit formulas derived, the optimum was found very rapidly. The marginal change in DOC with a different choice of objective function is shown in Fig. 15. The results of these optimizations are further detailed in Table 1, the first column showing the quantity minimized in the optimization, and the other columns being the relative change. (Note that positive values in Table 1 are reduc-
Table 1 Savings according to the choice of objective $\mathrm{e}^{\mathrm{a}}$

\begin{tabular}{lcrrr}
\hline \hline \multirow{2}{*}{$\begin{array}{l}\text { Panel } \\
\text { optimization }\end{array}$} & \multicolumn{4}{c}{ Savings } \\
\cline { 2 - 5 }$W^{\mathrm{b}}$ & \multicolumn{1}{c}{ Mat $^{\mathrm{c}}$} & MFC & DOC \\
\hline Minimum $W$ & 1.60 & -11 & 807 & 2898 \\
Minimum Mat & 0.99 & 36 & 680 & 2335 \\
Minimum MFC & $-2.29^{\mathrm{d}}$ & -108 & 1186 & 2872 \\
Minimum DOC & 0.58 & -26 & 1122 & 3539 \\
\hline \hline
\end{tabular}

$\overline{{ }^{a} \text { All cost savings are in U.S. dollars per square meter of panel, weight }}$ in kilograms per square meter.

${ }^{\mathrm{b}} W=$ total weight.

${ }^{\mathrm{c}}$ Mat $=$ bare material cost.

${ }^{\mathrm{d}}$ Negative values indicate an increase.

Table 2 Panel dimensions ${ }^{a}$ after optimization

\begin{tabular}{lcccccr}
\hline \hline Panel & & & & & & \\
optimization & $\eta$ & $b$ & $h$ & $t$ & \multicolumn{1}{c}{$t_{s}$} & \multicolumn{1}{c}{$r_{p}$} \\
\hline Efficiency $\eta$ & 0.693 & 42.8 & 27.6 & 0.85 & 1.61 & 31.1 \\
Minimum $W$ & 0.632 & 71.5 & 31.0 & $1.60^{\mathrm{b}}$ & $1.60^{\mathrm{b}}$ & 61.6 \\
Minimum Mat & 0.628 & 65.5 & 27.0 & 1.09 & 2.53 & 41.9 \\
Minimum MFC & 0.383 & 192.3 & 38.64 & 2.52 & 6.07 & 124.7 \\
Minimum DOC & 0.517 & 125.1 & 28.2 & 1.97 & 3.73 & 83.7 \\
\hline \hline
\end{tabular}

aAll dimensions in millimeters.

${ }^{\mathrm{b}}$ Limits of validity of local buckling data have been reached.

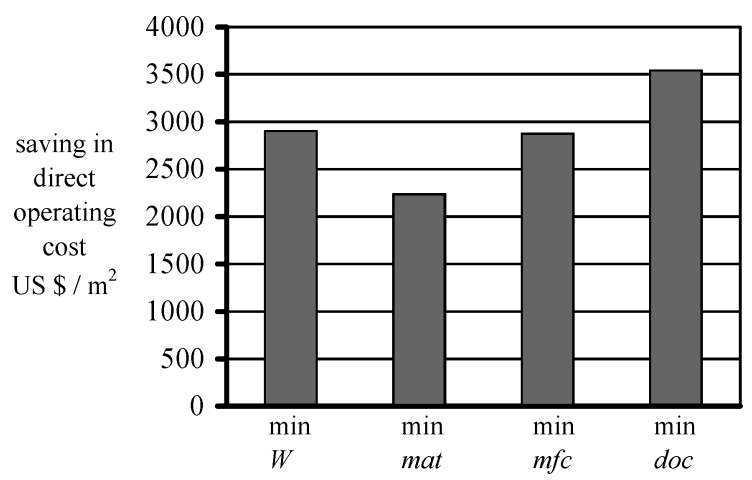

Fig. 15 Saving in direct operating cost according to choice of objective function (notation defined in Table 1).

tions relative to the reference panel, negative values indicating an increase.)

As can be seen in Table 1, substantial reduction in both weight and DOC are obtained when the panel is optimized for minimum total weight, rather than for maximum theoretical efficiency. This only emphasizes the importance of including the weight of connections and similar items in the optimization. Minimization of material cost, as well as total MFC, also show an improvement with regard to DOC, although minimization of MFC induces a weight penalty. Optimization for minimum DOC rather than for minimal weight shows a further improvement of $10 \%$ of the total DOC. This might be considered a favorable result because much structural optimization is performed for minimum weight, it being implicitly assumed that this also reduces cost. When optimized for minimum DOC, it was found that the ratio of AC to FB was typically 4:3. However, the present study is for a specific type of panel, lightly loaded and of relatively simple construction, and different results might be obtained in other situations.

Finally, note from Table 2 that the various criteria for optimization lead to widely differing panel dimensions. Minimization of DOC leads to a stringer pitch almost triple that of the theoretical optimum, at the same time more than doubling the skin and stringer thickness and the rivet pitch. Increased stringer pitch implies a reduced number of connecting cleats, and this together with increased rivet pitch leads to substantial cost savings in assembly. 


\section{Conclusions}

The main finding of the paper is that the minimal weight condition is not now synonymous with minimal DOC because it does not include the impact of MFC on AC. Rather, DOC is a function of both $\mathrm{AC}$ and $\mathrm{FB}$, and, therefore, there must be an inherent tradeoff between the preference to minimize weight or reduce MFC. It has been shown that the design optimization process can be achieved by linking MFC models with structural analysis models through shared design parameters. An original technique for modeling MFC using the genetic-causal approach was presented to facilitate the optimization process. Having such a design-oriented causal basis for the MFC is also crucial in being able to exploit new design approaches and manufacturing processes, rather than assuming that the minimal weight approach will continue to give a satisfactory answer for new technologies. Finally, the need to rebalance the structural design approach by giving preference to a reduction in MFC is a very attractive finding for the producer and the operator because both see a direct improvement for the industry. The price of the aircraft is reduced to make the producer more competitive, and the customer gains early through reduced AC and its through-life ramifications in financing. However, there is a shift in responsibility to the customer in that the operational cost of FB will go up, making the aircraft more susceptible to increased fuel costs as well as being less environmentally efficient.

\section{References}

${ }^{1}$ Wierda, L., "Design-Oriented Cost Information: The Need and the Possibilities," Journal of Engineering Design, Vol. 1, No. 2, 1990, pp. 147-167.

${ }^{2}$ Hoult, D. P., Meador, C. L., Deyst, J., and Dennis, M., "Cost Awareness in Design: The Role of Data Commonality," Society of Automotive Engineers, SAE Technical Paper, 1996.

${ }^{3}$ Sheldon, D. F., Huang, G. Q., and Perks, K., "Design for Cost: Past Experience and Recent Development," Journal of Engineering Design, Vol. 2, No. 2, 1991, pp. 127-139.

${ }^{4}$ Dean, E. B., and Unal, R., "Elements of Designing for Cost," Proceedings of AIAA 1992 Aerospace Design Conference, AIAA, Washington, DC, 1992.

${ }^{5}$ Michael, J., and Wood, W., Design to Cost, Wiley Interscience, 1989.

${ }^{6}$ Curran, R., Rush, C., Roy, R., and Raghunathan, S., "Cost Estimating Practice in Aerospace: England and Northern Ireland," Proceedings of CE2002 Conference on Concurrent Engineering: Research and Applications, 2002.

${ }^{7}$ Rush, C., and Roy, R., "Analysis of Cost Estimating Processes Used Within a Concurrent Engineering Environment Throughout a Product Life Cycle," Proceedings of CE2000 Conference on Concurrent Engineering: Research and Applications, 2000, pp. 58-67.

${ }^{8}$ Heinmuller, B., and Dilts, D. M., "Automated Design-to-Cost: Application in the Aerospace Industry," Annual Meeting of the Decision-ScienceInstitute, Vol. 1-3, 1997, Chaps. 569, pp. 1227-1229.

${ }^{9}$ Gieger, T. S., and Dilts, D. M., "Automated Design-to-Cost: Integrating Costing into the Design Decision," Computer Aided Design, Vol. 28, No. 6/7, 1996, pp. 423-438.

${ }^{10}$ Brimson, J. A., and Downey, P. J., "Feature Technology: A Key to Manufacturing Integration," CIM Review, Vol. 2, No. 3, 1986, pp. 21-27.

${ }^{11}$ Bashir, H. A., and Thompson, V., "Estimating Design Complexity," Journal of Engineering Design, Vol. 10, No. 3, 1999, pp. $248-257$.

${ }^{12}$ Cooper, R., and Kaplan, R. S., "Measure Cost Right: Make the Right Decisions," Harvard Business Review, Vol. 66, No. 5, 1988, pp. 96-103.

${ }^{13}$ Cokins, G., "ABC Can Spell a Simpler, Coherent View of Costs," Computing Canada, Sept. 1998.

${ }^{14}$ Taylor, I. M., "Cost Engineering-A Feature Based Approach," Proceedings of the 85th Meeting of the AGARD Structures and Material Panel, AGARD, 1997, Chap. 14, pp. 1-9.

${ }^{15}$ Curran, R., Eakin, D., Price, M., Gibson, A., and Murphy, A., "Linking Engineering Costs and DFMA for Integrated Aerospace Design," Proceedings of CE2O03 Conference on Concurrent Engineering: Research and Applications, 2003.

${ }^{16}$ Curran, R., Kundu, A., Raghunathan, S., and Eakin, R., "Costing Tools for Decision Making Within Integrated Aerospace Design," Journal of Concurrent Engineering Research, Vol. 9, No. 4, 2002, pp. $327-338$.
${ }^{17}$ Smith, A. E., and Mason, A. K., "Cost Estimation Predictive Modelling: Regression versus Neural Network," Engineering Economist, Vol. 42, No. 2, 1997, pp. 137-162.

${ }^{18}$ Villarreal, J. A., Lea, R. N., and Savely, R. T., "Fuzzy Logic and Neural Network Technologies," Proceedings of the 30th Aerospace Sciences Meeting and Exhibit, 1992.

${ }^{19}$ Bode, J., "Neural Networks for Cost Estimation," American Association of Cost Engineers, Vol. 40, No. 1, 1998, pp. 25-30.

${ }^{20}$ Parametric Estimating Handbook, 2nd ed., U.S. Dept. of Defense, 1999, URL: http://www.ispa-cost.org/PEIWeb/cover.htm [cited 28 June 2004].

${ }^{21}$ Roy, R., Bendall, D., Taylor, J. P., Jones, P., Madariaga, A. P., Crossland, J., Hamel, J., and Taylor, I. M., "Development of Airframe Engineering CERs for Military Aerostructures," Proceedings of the Second World Manufacturing Congress (WMC'99), 1999.

${ }^{22}$ Pugh, P., "Working Top-Down: Cost Estimating Before Development Begins," Journal of Aerospace Engineering, Pt. G, Vol. 206, 1992, pp. 143-151.

${ }^{23}$ Thurston, D. L., and Essington, S. K., "A Tool for Optimal Manufacturing Design Decisions," Manufacturing Review, Vol. 6, No. 1, 1993 , pp. $48-59$.

${ }^{24}$ Keeney, R. L., and Raiffa, H., Decisions with Multiple Objectives: Preferences and Value Trade-offs, Wiley, New York, 1976.

${ }^{25}$ Vanderplaats, G. N., Numerical Optimization Techniques for Engineering Design: with Applications, McGraw-Hill, 1984.

${ }^{26}$ Collopy, P. D., and Eames, D. J. H., "Aerospace Manufacturing Cost Prediction from a Measure of Part Definition Information," Society of Automotive Engineers Publications, Warrendale, PA, 2001.

${ }^{27}$ Kundu, A., Raghunathan, S., and Cooper, R. K., "Effect of Aircraft Smoothness Requirements on Cost," Aeronautical Journal, Vol. 104, No. 1039 , 2000, pp. 415-420.

${ }^{28}$ Butterfield, J., Yao, H., Curran, R., Price, M., Armstrong, C. G., Raghunathan, S., "Integration of Aerodynamic, Structural, Cost and Manufacturing Considerations During the Conceptual Design of a Thrust Reverser Cascade," 42nd AIAA Aerospace Sciences Meeting and Exhibit, Jan. 2004

${ }^{29}$ Marx, W. J., Mavris, D. N., and Schrage, D. P., "Effects of Alternative Wing Structural Concepts on High Speed Civil Transport Life Cycle Costs," Proceedings of 37th AIAA/ASME/AHS/ASC Structures, Structural Dynamics, and Materials Conference, AIAA, Reston, VA, 1996.

${ }^{30}$ Raymer, D. P., Aircraft Design: A Conceptual Approach, AIAA Educational Series, AIAA, Reston, VA, 1999.

${ }^{31}$ Westphal, R., and Scholz, D. A., "Method for Predicting Direct Operating Costs During Aircraft System Design," Cost Engineering, Vol. 39, No. 6, 1997, pp. 35-39.

${ }^{32}$ Curran, R., Kundu, A., Raghunathan, S., and McFadden, R., "Influence of Manufacturing Tolerance on Aircraft Direct Operating Cost (DOC)," Journal of Materials Processing Technology, 2003, pp. 239-247.

${ }^{33}$ Boothroyd, G., and Dewhurst, P., Product Design for Assembly, Boothroyd Dewhurst, Wakefield, RI, 1990

${ }^{34}$ Stoll, H. W., "Design for Manufacture: an Overview," Applied Mechanics Review, Vol. 39, No. 9, 1986, pp. 1356-1364.

${ }^{35}$ Bloom, H. M., "Design for Manufacturing and the Life Cycle," Proceeding of the NSF Design Theory 88 Conference, National Science Foundation, 1988, pp. 302-312.

${ }^{36}$ Murman, E. M., Walton, M., and Rebentisch, E., "Challenges in the Better, Faster, Cheaper, Era of Aeronautical Design, Engineering and Manufacturing," Aeronautical Journal, 2000, pp. 481-488.

${ }^{37}$ Rais-Rohani, M., "A Framework for Preliminary Design of Aircraft Structures Based on Process Information," NASA Grant NAG-1-1716, 1998.

${ }^{38}$ Rais-Rohani, M., and Greenwood, A. G., "Product and Process Coupling in Multidisciplinary Design of Flight Vehicle Structures," Proceedings of the 7th AIAA/NASA/USAF/ISSMO Symposium on Multidisciplinary Analysis and Optimization, AIAA, Reston, VA, 1998.

${ }^{39}$ Sandoz, P. L., "Structural Design of Future Commercial Transports," Proceedings of the 9th Annual Meeting and Technical Display, 1973.

${ }^{40}$ Noton, B. R., "Cost Drivers in Design and Manufacture of Composite Structures," Composite Structures Analysis and Design, 1987, pp. 419-428.

${ }^{41}$ Noton, B. R., "Cost Drivers and Design Methodology for Automated Airframe Assembly," Proceedings of 31st Intenational SAMPE Symposium, Society for the Advancement of Material and Process Engineering, 1986, pp. 1441-1455. 
${ }^{42}$ Ermanni, P., and Ziegmann, G., "Cost-Efficiency of Highly Integrated Fuselage Structures-Comparison Between Metals and Composites," Proceedings of SAMPE Advanced Materials: Cost Effectiveness, Quality Control, Health and Environment, Society for the Advancement of Material and Process Engineering, 1991, pp. 347-359.

43" Local Buckling of Compression Panels with Unflanged Integral Stiffeners," Engineering Sciences Data Unit, ESDU International, Item 70003 (Structures Series), 1970.

44"Buckling in Compression of Sheet Between Rivets," Engineering Sciences Data Unit, ESDU International, Item 02.01.08 (Structures Series), 1962.
${ }^{45}$ Rothwell, A., "Structural Optimisation," Lecture Notes, Faculty of Aerospace Engineering, Delft Univ. of Technology, Delft, The Netherlands, 2004.

${ }^{46}$ Curran, R., Kundu, A., Raghunathan, S., and McFadden, R., "Impact of Aerodynamic Surface Tolerance on Aircraft Cost Driver," Journal of Aerospace Engineering, Vol. 216(G1), 2002, pp. 2939.

${ }^{47}$ Curran, R., Watson, P., Cowan, S., Mahwinney, P., and Raghunathan, S., "Development of an Aircraft Cost Estimating Model for Program Cost Rationalisation," Proceedings of the Canadian Aeronautics and Space Institute (CASI), 2003. 